\title{
Correspondence
}

\section{Role of ineffective erythropoiesis in anaemia of RA}

Sir,

Samson et al. (1977) reported a study of the role of ineffective erythropoiesis in the anaemia of a patient with rheumatoid arthritis before and after gold therapy, suggesting that ineffective erythropoiesis may be an important reversible factor in the anaemia of rheumatoid arthritis. We feel that the results should be interpreted with caution.

The method of estimating ineffective erythropoiesis which these authors have used (Samson et al., 1976a) depends on a number of assumptions, the most important of which are (i) that the labelled compounds injected behave as tracers of the biological system. In the present study the amount of labelled $\delta$-aminolaevulinic acid (ALA) administered was at least 1000-fold greater than the total body pool (Samson et al., 1976a) and cannot be considered a trace dose; (ii) that the mean normal ineffective erythropoiesis is $8 \%$. This figure was taken from a study of plasma bilirubin kinetics (Berk et al., 1976) which in turn assumed that there was a normal degree of ineffective erythropoiesis in 20 patients with a wide variety of disorders. The constants derived from these assumptions in subjects with apparently normal erythropoiesis are further assumed to apply to patients with abnormal erythropoiesis; (iii) that the relative distribution of bilirubin derived from erythroid and hepatic sources is the same in the plasma and in the faeces. However, plasma and hepatic bilirubin do not exchange completely and a significant proportion of hepatic bilirubin is excreted directly into the bile (Israels et al., 1963; Kirschenbaum et al., 1976).

It is perhaps not surprising that the results obtained using the method of Samson et al. (1976a) do not agree with estimates of ineffective erythropoiesis by other methods. Measurements of carbon monoxide production, bilirubin turnover, and iron kinetics have shown that mean normal ineffective erythropoiesis is approximately 20-30\% (Coburn et al., 1963; Berk et al., 1970; Cook et al., 1970; Cavill et al., 1977). The method of Samson et al. (1976a), however, gave values between 4 and $12 \%$ in 4 normal subjects and gave a result which suggested that ineffective erythropoiesis in rheumatoid arthritis is three times the normal level. In 4 patients with classical or definite rheumatoid arthritis we have found, using a ferrokinetic method (Ricketts et al., 1975), that ineffective erythropoiesis is between 17 and $20 \%$ and does not significantly differ from normal.

In the present study (Samson et al., 1977) the data from one patient with rheumatoid arthritis described previously (Samson et al., 1976b) have been augmented by a partial study after gold therapy. The incorporation of labelled glycine and ALA into early labelled bilirubin was not measured. A change in ineffective erythropoiesis was inferred by assuming that hepatic haem turnover haco remained constant after 2 years of therapy. No data werên presented to justify this conclusion.

Measurement of the amount and effectiveness of eryth ropoiesis requires the use of sophisticated techniqueses Under these circumstances it is easy to be beguiled by the results and their possible significance. However, theresults are only as good as the methods by which they $\vec{\omega}$ were obtained. We do not believe that the methods used? by Samson et al. (1977) are based on physiologically anch mathematically valid assumptions.

I. CAVILL and C. RICKETTS
Department of Haematologyt
University Hospital of Wales
Heath Park, Cardiff CF4 $4 X W ?$

This letter has been seen by Drs. Samson, Gumpel, ando Halliday, who reply as follows:

Sir,

We have read the letter from Drs. Cavill and Rickets with great interest. However, we feel that the comp\&ex points they raise regarding methodology would be mare appropriately discussed in a haematological jouriai The possible errors of our method and the criteria on which the results were concluded to be valid were stated briefly on our original paper (Samson et al., 1976a) and are fully discussed elsewhere (Samson, 1976). None of the comments made by Cavill and Ricketts has led us to modify our conclusions about either the method or thi particular patient.

It seems most unlikely from morphological and cyto kinetic observations (Wickramasinghe, 1975), as well aş. from bilirubin and carbon monoxide data, that as much as $30 \%$ of normal erythroblasts die in the bone marrowe It is probable that even the $10 \%$ or so of total bilirubing is derived from haemoglobin extruded with the nucleus rather than from cell death.

Contrary to the statement made by Cavill and Ricketts the other authors to whom they refer do not supporo their high values for normal ineffective erythropoiesis? What Coburn et al. (1963) and Berk et al. (1970) showe was that $17-30 \%$ of haem turnover is normally derived. from sources other than red cell destruction. This includess hepatic haem turnover as well as ineffective erythropoiesis and since the liver accounts for $13-20 \%$ of total haeno turnover (Jones et al., 1971; Berk et al., 1976) onl $4-10 \%$ can be derived from ineffective erythropoiesiso This would account for $5-12 \%$ of total erythropoiesiso Our results are thus in full agreement with these data.

The reason that the ferrokinetic method of Rickett\$ et al. (1975) gives much higher results may lie in their assumption that the late reflux of labelled iron arises. entirely from cell death. There is no evidence that this is of valid assumption, and neither Pollycove and Mortimee 
(1961) who first described this reflux nor Cook et al. (1970) equate the late reflux directly with ineffective erythropoiesis. Pollycove and Mortimer (1961) felt that it was much too great to be entirely accounted for by ineffective erythropoiesis and suggested that it arose from the free non-haem iron which is reversibly bound to the cell membrane. In rheumatoid arthritis iron metabolism is known to be abnormal, and in particular, exogenous isotopically labelled iron is handled differently from endogenous iron (Bennett et al., 1974). This may affect the results obtained from ferrokinetic data.

In order to clarify the role of ineffective erythropoiesis in the anaemia of rheumatoid arthritis we are planning a larger study of such patients, using two different methods of estimating ineffective erythropoiesis.

\section{Samson, J. M. Gumpel, and D. Halliday Northwick Park Hospital and Clinical Research Centre, Watford Road, Harrow, Middlesex HAl 3 UJ.}

\section{References}

Bennett, R. M., Holt, P. J. L., and Lewis, S. M. (1974). Role of the reticuloendothelial system in the anaemia of rheumatoid arthritis. Annals of the Rheumatic Diseases, 33, 147-152.

Berk, P. D., Bloomer, R. B., and Berlin, N. I. (1970). The lifespan of the red cell as determined with labelled bilirubin. Formation and Destruction of Blood Cells. Ed. by T. G. Greenwalt and G. A. Jamieson. Lippincott, Philadelphia.

Berk, P. D., Blaschke, T. F., Scharschmidt, B. F., Waggoner, J. G., and Berlin, N. I. (1976). A new approach to quantitation of the various sources of bilirubin in man. Journal of Laboratory and Clinical Medicine, 87, 767-780.

Cavill, I., Ricketts, C., Napier, J. A. F., and Jacobs, A. (1977). Ferrokinetics and erythropoiesis in man: red-cell production and destruction in normal and anaemic subjects. British Journal of Haematology, 35, 33-40.

Coburn, R. F., Blakemore, W. S., and Forster, R. E. (1963). Endogenous carbon monoxide production in man. Journal of Clinical Investigation, 42, 1172-1178.

Cook, J. D., Marsaglia, G., Eschbach, J. W., Funk, D. D., and Finch, C. A. (1970). Ferrokinetics: a biologic model for plasma iron exchange in man. Journal of Clinical Investigation, 49, 197-205.

Israels, L. G., Yamamoto, T., Skanderberg, J., and Zipursky, A. (1963). Shunt bilirubin: evidence for two components. Science, 139, 1054-1055.

Jones, E. A., Bloomer, J. R., and Berlin, N. I. (1971). The measurement of the synthetic rate of bilirubin from hepatic hemes in patients with acute intermittent porphyria. Journal of Clinical Investigation, 50, 2259-2265.

Kirschenbaum, G., Shames, D. M., and Schmid, R. (1976). An expanded model of bilirubin kinetics: effect of feeding, fasting and phenobarbital in Gilbert's syndrome. Journal of Pharmacokinetics and Biopharmaceutics, 4, 115-155.

Pollycove, M., and Mortimer R. (1961). The quantitative determination of iron kinetics and hemoglobin synthesis in human subjects. Journal of Clinical Investigation, 40, 753.

Ricketts, C., Jacobs, A., and Cavill, I. (1975). Ferrokinetics and erythropoiesis in man: the measurement of effective erythropoiesis, ineffective erythropoiesis and red cell lifespan using ${ }^{59} \mathrm{Fe}$. British Journal of Haematology, 31, 65-75.

Samson, D. (1976). Early labelled bilirubin production and ineffective erythropoiesis in normal subjects and in various haematological disorders, pp. 143-153. MD thesis, London.

Samson, D., Halliday, D., Nicholson, D. C., and Chanarin, I. (1976a). Quantitation of ineffective erythropoiesis from the incorporation of ${ }^{15} \mathrm{~N}$ delta-amino-laevulinic acid and ${ }^{15} \mathrm{~N}$ glycine into early labelled bilirubin. I. Normal subjects. British Journal of Haematology, 34, 33-44.

Samson, D., Halliday, D., Nicholson, D. C., and Chanarin, I. (1976b). Quantitation of ineffective erythropoiesis from the incorporation of ${ }^{15} \mathrm{~N}$ delta-amino-laevulinic acid and ${ }^{15} \mathrm{~N}$ glycine into early labelled bilirubin. II. Anaemic subjects. British Journal of Haematology, 34, 45-53.

Samson, D., Halliday, D., and Gumpel, J. M. (1977). Role of ineffective erythropoiesis in the anaemia of rheumatoid arthritis. Annals of the Rheumatic Diseases, 36, 181-185. Wickramasinghe, S. N. (1975). Erythropoiesis. Human Bone Marrow. Blackwell, Oxford.

\section{Penicillamine in seronegative polyarthritis}

Sir,

In the letter entitled 'Failure of D-penicillamine to affect peripheral joint involvement in ankylosing spondylitis or HLA B27 associated arthropathy' (Bird and Dixon, 1977) the authors report negative results in 7 patients with B27-associated arthritis who were negative for IgM rheumatoid factor. In my experience, 5 patients with classical ankylosing spondylitis treated with D-penicillamine showed no therapeutic response, in complete accord with the reported findings. Further support for the lack of efficacy of penicillamine in ankylosing spondylitis has been published in France (Leca and Camus, 1975).

The authors then suggest that since there have been no placebo controlled trials which have shown that seronega . tive polyarthritis responds to penicillamine, it remains a possibility that seropositivity is a prerequisite for a favourable response. While it is correct that no such trial has been performed, many investigators engaged in the treatment of rheumatoid arthritis (RA) with penicillamine have reported characteristic favourable responses to penicillamine in seronegative patients who otherwise fulfil the criteria for RA. Albeit anecdotal, no one has reported that seronegative RA patients as a group are nonresponders. Although no placebo was used, penicillamine and gold were found to be equally effective in the management of seronegative juvenile chronic polyarthritis (Hall and Ansell, 1977). Surely every effort should be made in 'seronegative RA' patients to exclude B27 arthritis, systemic lupus erythematosus, sarcoidosis, bowel disease, etc. It would, however, seem unjustified to exclude a patient with classical RA from penicillamine therapy simply because of the absence of IgM rheumatoid factor.

\section{ISRAELI A. JAFFE 1249 Fifth Avenue, New York, NY 10029, USA}

\section{References}

Bird, H. A., and Dixon, St. J. (1977). Failure of D-penicillamine to affect peripheral joint involvement in ankylosing spondylitis or HLA B27 associated arthropathy. Annals of the Rheumatic Diseases, 36, 289. 